\title{
Prostate cancer solitary metastasis to anal canal: case report and review of literature
}

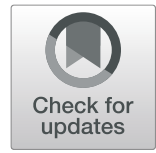

\author{
Audrius Dulskas ${ }^{1,2,3^{*}}$ (D) Vaidas Cereska ${ }^{1}$, Edvardas Zurauskas ${ }^{4}$, Eugenijus Stratilatovas ${ }^{1}$ and Feliksas Jankevicius ${ }^{5}$
}

\begin{abstract}
Background: Here we present the first cases of prostate cancer solitary metastasis to anal canal.

Case presentation: A 67-year-old male patient underwent radical prostatectomy with ilio-obturator lymphonodectomy in 2016 due to poorly differentiated ductal adenocarcinoma (Gleason $4+5(40 \%)=9$ ) pT3bNO. Two months later increasing PSA rate was noted and the patient started adjuvant intermittent androgen deprivation therapy combined with radiotherapy. Year after patient was admitted to the hospital complaining of dyschezia, pain in anal canal, and bloody stool. Digital rectal examination revealed an anal fissure with ulceration. A biopsy from ulcerated area showed poorly differentiated ductal adenocarcinoma of the prostate. Because there was no evidence of distant metastases on abdominal computed tomography (CT) scan and pelvic magnetic nuclear resonance imaging (MRI) and the only metastasis was in anal canal patient underwent laparoscopic abdominoperineal resection (APR). Postoperative course was uneventful and patient was discharged at postoperative day 7.

Conclusions: Our presented case is the first to describe prostate cancer solitary metastasis to anal canal and we always have to be aware of possible rare disease while assessing the patient with rectal bleeding. Biopsy most of the time is the only and the most reliable test to differentiate between the diseases.
\end{abstract}

Keywords: Prostate cancer, Prostate cancer metastasis, Metastatic anal canal tumour, Abdominoperineal excision, Solitary metastasis, Case report

\section{Background}

Prostate cancer is a second most common cancer in males worldwide with more than 1200 million new cases diagnosed in 2018 [1]. In Lithuania it is the most common cancer in men with incidence up to 189,4 per 100,000 in 2012 [2]. The metastatic pattern of advanced prostate cancer is well known with bone tissue being the most dominant site for metastasis. Other sites of involvement are distant lymph nodes, liver, thorax, brain, digestive system, retroperitoneum, kidney and adrenal gland [3]. Finding prostate adenocarcinoma $(\mathrm{PCa})$ metastasis in digestive tract is very unusual. Studies distinguishing solitary prostate cancer metastases to colon and rectum are very rare. Until now only six cases can be found in literature reporting on solitary metastasis to colon and rectum [4-9].

Here we report an exceptionally rare case of prostate adenocarcinoma solitary metastasis in anal canal. This is the first case being reported in the literature.

\section{Case presentation}

* Correspondence: audrius.dulskas@gmail.com
1Department of General and Abdominal Surgery and Oncology, National Cancer Institute, 1 Santariskiu Str., LT-08406 Vilnius, Lithuania

${ }^{2}$ Department of General and Abdominal Surgery and Oncology, National Cancer Institute, Clinic of Internal, Family Medicine and Oncology, Faculty of Medicine, 1 Santariskiu Str., LT-08660 Vilnius, Lithuania

Full list of author information is available at the end of the article
Written informed consent was obtained from the patient for publication of this case report and accompanying images. Institutional Review Board permission was granted. 


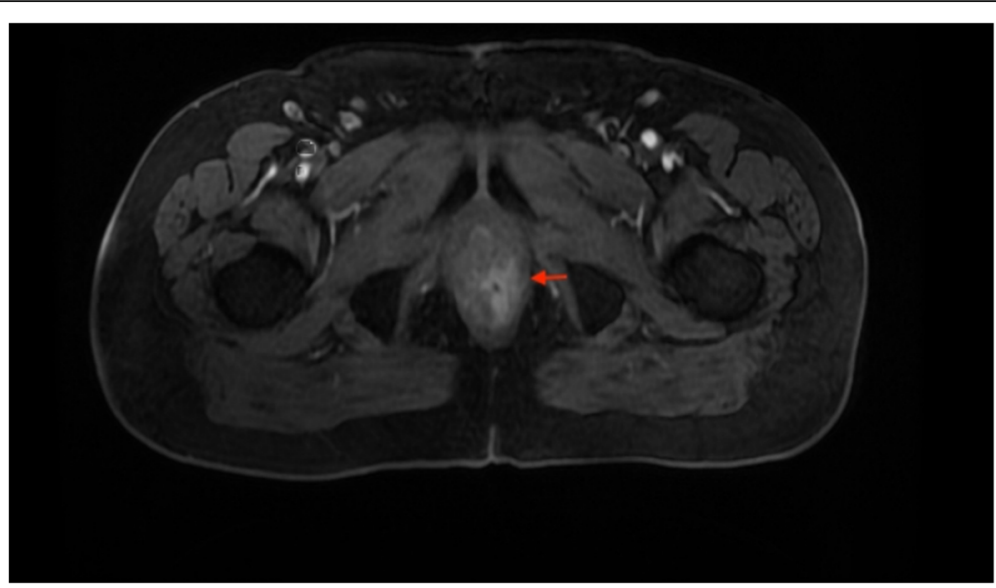

Fig. 1 T2 transversal view. Slightly enlarged left rectum wall with a slight increase of contrast. Accumulation (red arrow)

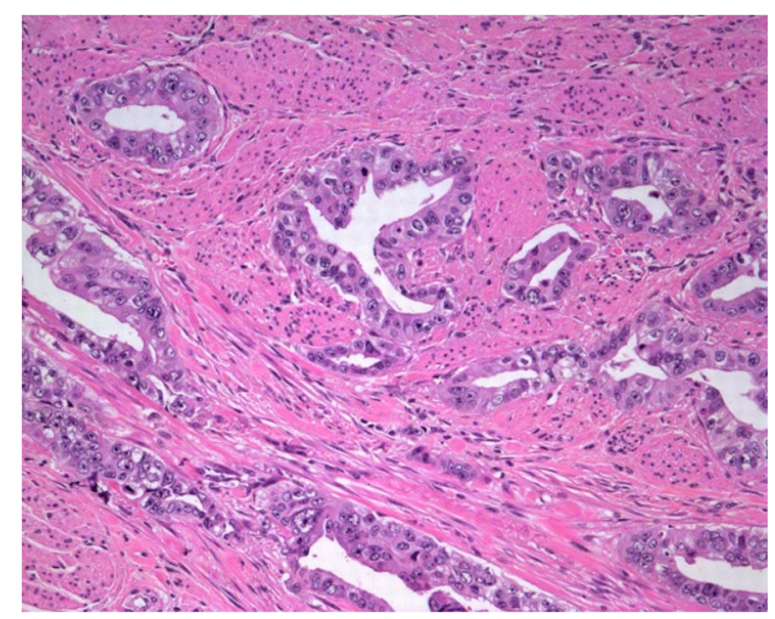

Fig. 2 H\&Ex100. Carcinoma of prostate show bowel muscular wall invasion by irregular malignant glands with enlarged nuclei, prominent nucleoli and dark cytoplasm

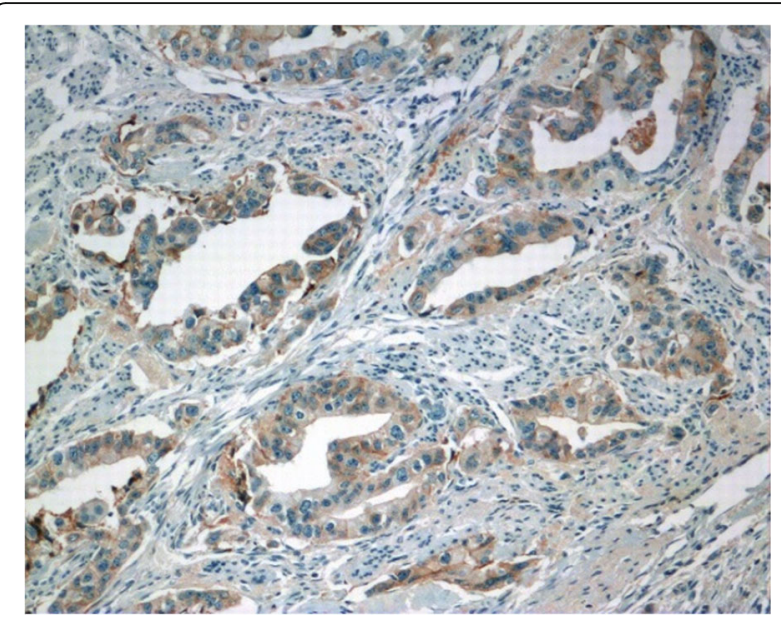

Fig. 3 PSAx100. Malignant glands are positive for prostate specific antigen (PSA)

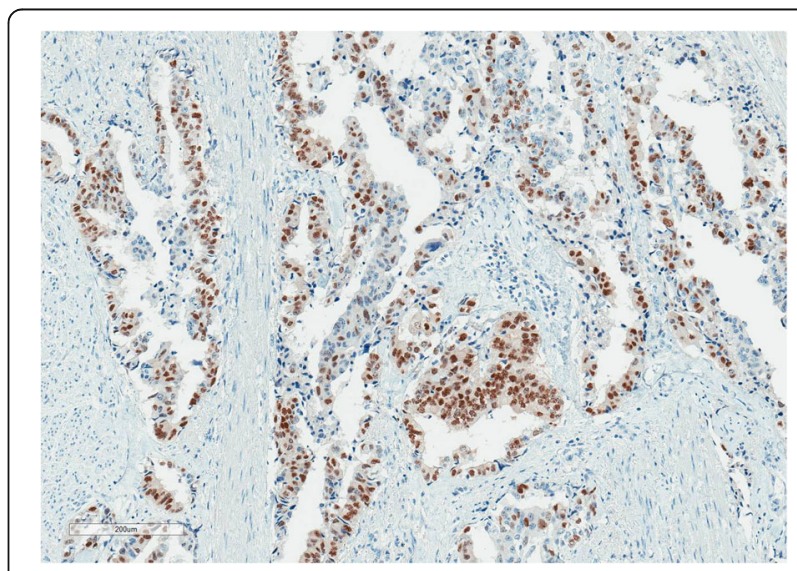

Fig. 4 NKX3.1 $\times 100$. Malignant glands are positive for NKX3.1

A 67-year-old male patient smoker (smokes 10 cigarettes/day) with BMI of 28.7 underwent transrectal needle biopsy of the prostate in July 2015 due to elevated prostate-specific antigen (PSA) level of $7.02 \mathrm{ng} /$ $\mathrm{mL}$ and firm nodule with infiltration of the capsule on digital rectal examination. The patient had no previous history of faecal occult blood testing, prostate biopsies or surgeries performed. Biopsy revealed poorly differentiated ductal adenocarcinoma Gleason $4+4$. Imunohistochemical analysis was positive for p504s and negative for PSA, CK20, CK7, and CDX2. The patient received hormonal treatment with Leuprorelin acetate for 9 months. Pelvic magnetic nuclear resonance imaging (MRI) showed tumour in both prostate lobes and infiltration to semi vesicles mrT3bN0 PI-RADS - 5 (Prostate Imaging Reporting and Data System). Staging of computed tomography (CT) of the abdomen and pelvis and Tc- $99 \mathrm{~m}$ bone scan showed no radiological evidence of metastatic spread. Patient was advised to undergo surgery. 


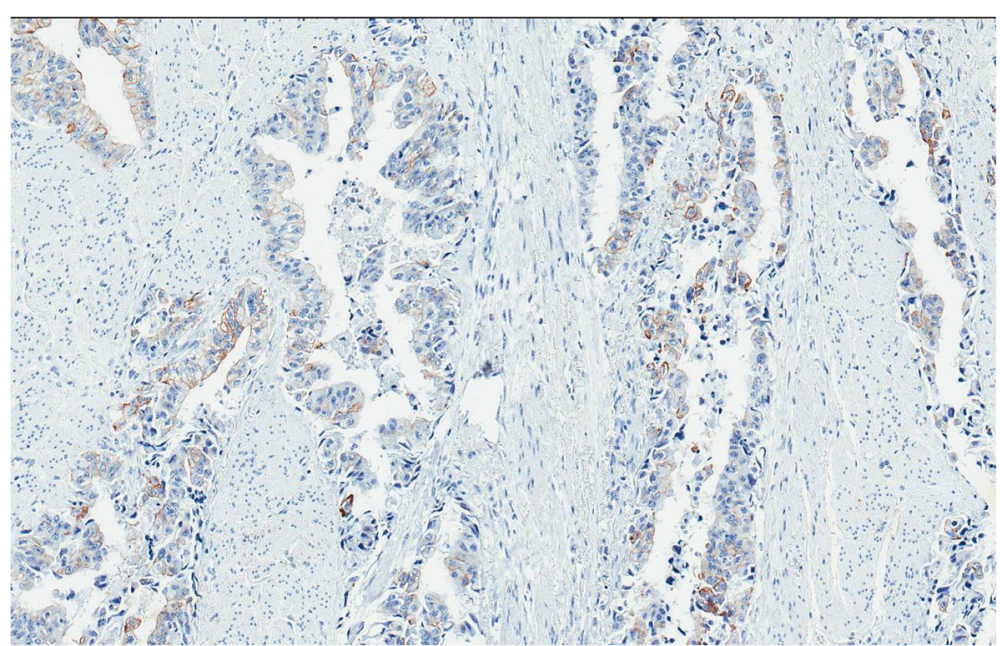

Fig. 5 CKHMWX100. Malignant glands are positive for CKHMW

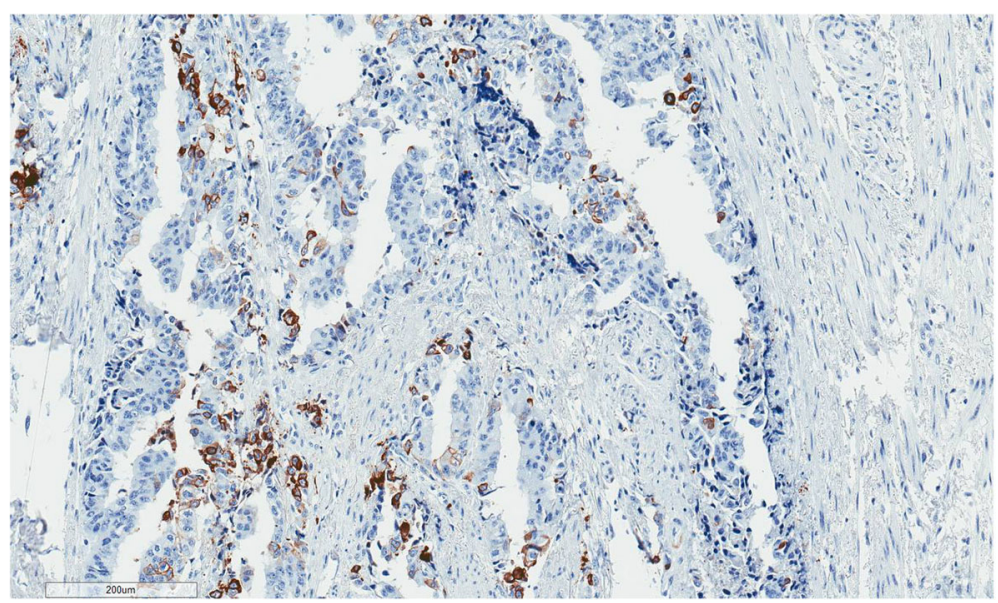

Fig. 6 CK7×100. Malignant glands are negative for CK7

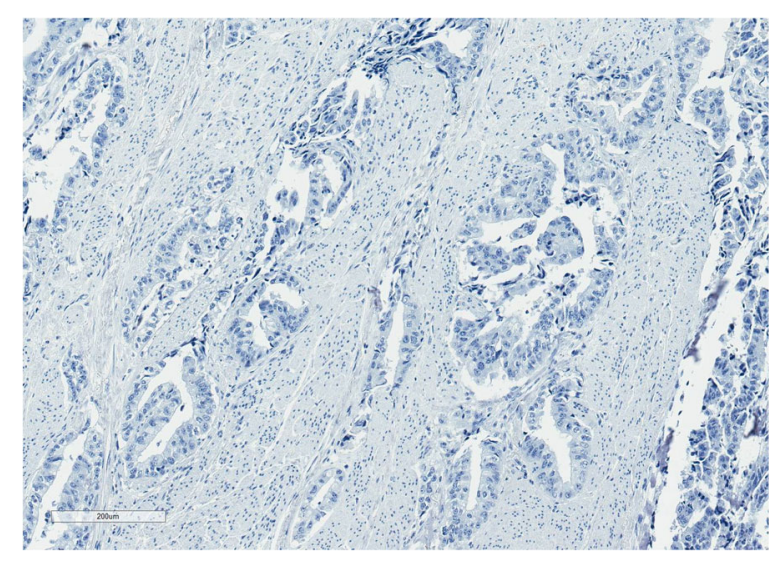

Fig. 7 p63×100. Malignant glands are negative for p63
In October 2016, radical retropubic prostatectomy and ilio-obturator lymphonodectomy was performed. Pathological findings demonstrated poorly differentiated ductal adenocarcinoma (Gleason $4+5(40 \%)=9$ ) pT3bN0, LV1. PSA value 2 months after operation was $0,126 \mathrm{ng} / \mathrm{ml}$ and increased up to $0,358 \mathrm{ng} / \mathrm{ml}$ over four-month period which was stated as a recurrence. Patient was started on adjuvant intermittent androgen deprivation therapy combined with radiotherapy.

In August 2017, patient received 2 phase radiotherapy: first phase to prostate bed, remnant seminal vesicles and regional lymph nodes up to $50 \mathrm{~Gy}$ and second phase to prostate bed and remnant seminal vesicles up to $70 \mathrm{~Gy}$. The PSA levels decreased, however 4 months later patient complained of mild pain in anal verge. 


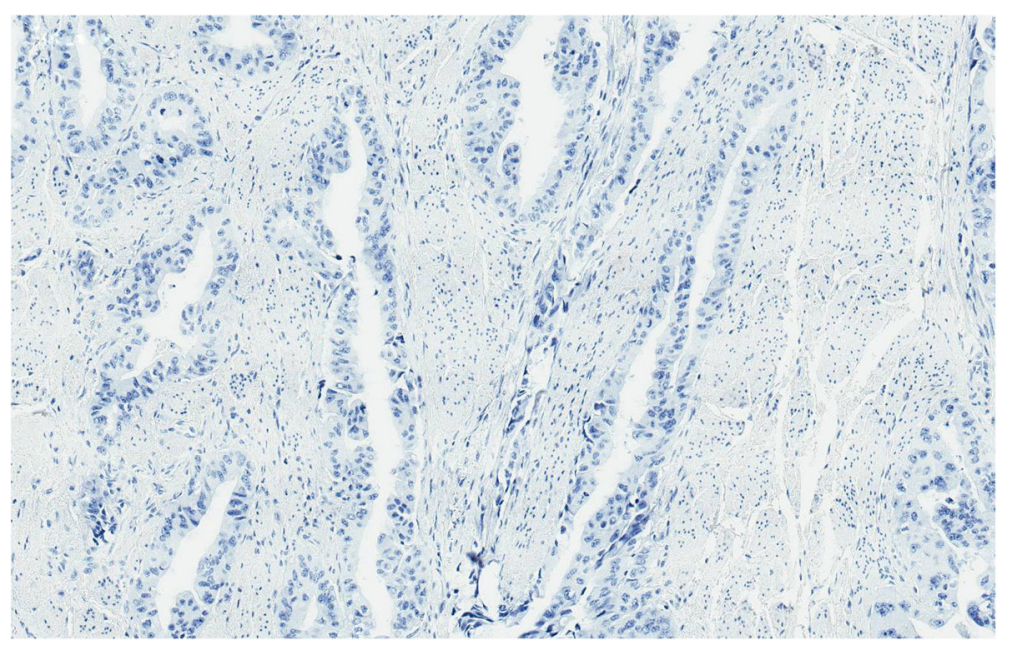

Fig. 8 CDX2X100. Malignant glands are negative for CDX2

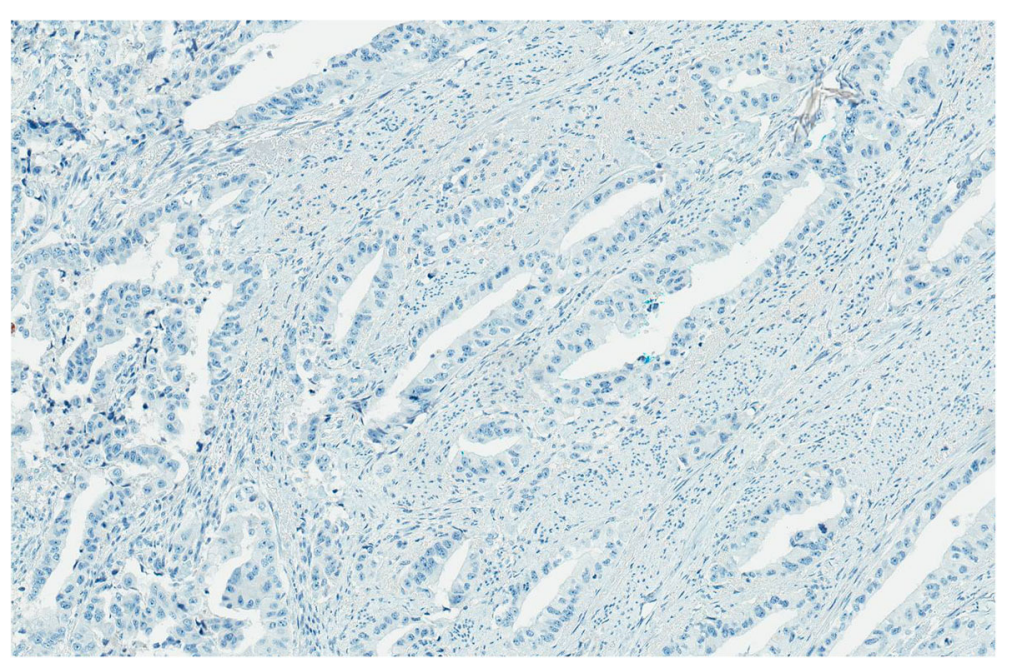

Fig. 9 CK20×100. Malignant glands ar negative for CK20

In May 2018, slight tenderness on 12 o'clock was noted during digital rectal examination. On rectoscopy the rectal and anal mucosa was found without any changes. Chest, abdomen and pelvic CT scan did not reveal any signs of recurrence.

In June 2018, the patient was admitted to the hospital complaining of dyschezia, pain in anal canal, and bloody stool. Anal inspection and palpation revealed an anal fissure with ulceration. A biopsy from ulcerated area was taken. Histologic examination reported poorly differentiated ductal adenocarcinoma of the prostate extending to muscle layer with NKX3.1, PSA, CKHMW, positive staining. MRI scan (Fig. 1) showed slightly enlarged rectum wall in anal canal with a slight increase of contrast accumulation and small nodules on the left rectum wall.
Because of anal pain, bloody stool, prostatic metastasis verified, and no evidence of distant metastases, the only metastasis was in the anal canal, patient underwent laparoscopic abdominoperineal resection (APR) in August 2018. Histopathologic findings from the resected specimen showed ductal prostate cancer at the dentate line extending to the fat tissue and infiltrating mucosa, submucosa and muscle layers of the anus (Figs. 2, 3, 4, 5, 6, 7,8 and 9). One of five lymph node had prostate cancer metastasis. Post-operative course was uneventful and on post-operative day 7 , patient was discharged. Patients PSA was less than $0.2 \mathrm{ng} / \mathrm{ml}$.

\section{Discussion}

According to studies by Gandaglia et al., metastases in bone tissue account for $84-90 \%$ of advanced 
Table 1 Literature review of all previous cases of solitary prostate cancer metastasis to colon and rectum

\begin{tabular}{|c|c|c|c|c|c|c|c|}
\hline $\begin{array}{l}\text { Author/Year } \\
\text { of publication }\end{array}$ & Age & Symptoms & $\begin{array}{l}\text { Gleason } \\
\text { score }\end{array}$ & $\begin{array}{l}\text { Interval between original PCa } \\
\text { diagnosis and rectal presentation }\end{array}$ & $\begin{array}{l}\text { Tumour } \\
\text { grade/Type }\end{array}$ & $\begin{array}{l}\text { PSA staining in } \\
\text { colon specimens }\end{array}$ & Treatment \\
\hline $\begin{array}{l}\text { Morita et al. } \\
1991[6]\end{array}$ & 61 & $\begin{array}{l}\text { obstructive } \\
\text { defecation }\end{array}$ & n.d & 5 months & $\begin{array}{l}\text { G3 / } \\
\text { adenocarcinoma }\end{array}$ & positive & AAT/total pelvic exenteration \\
\hline $\begin{array}{l}\text { Vaghefi et al. } \\
2005[4]\end{array}$ & 69 & no symptoms & $3+4=7$ & 5 years & $\begin{array}{l}\mathrm{G} 2 / \\
\text { adenocarcinoma }\end{array}$ & positive & $\mathrm{RP}$ with pelvic lymphadenectomy/LE \\
\hline $\begin{array}{l}\text { Fujita et al. } \\
2009[7]\end{array}$ & 77 & abdominal pain & n.d & same time & $\begin{array}{l}\text { G3 / } \\
\text { adenocarcinoma }\end{array}$ & positive & AAT \\
\hline $\begin{array}{l}\text { Venara et al. } \\
2010[5]\end{array}$ & 75 & abdominal pain & $3+4=7$ & 10 years & $\begin{array}{l}\text { prostatic } \\
\text { carcinosarcoma }\end{array}$ & n.d & $\begin{array}{l}\text { RP/ AAT and pelvic RT/intermittent } \\
\text { hormonal treatment/ AR/radiotherapy }\end{array}$ \\
\hline $\begin{array}{l}\text { Nwankwo } \\
\text { et al. } 2013[8]\end{array}$ & 69 & $\begin{array}{l}\text { rectal bleeding, } \\
\text { abdominal pain }\end{array}$ & n.d & 12 years & $\begin{array}{l}\mathrm{G} 3 \text { / } \\
\text { adenocarcinoma }\end{array}$ & n.d & $\begin{array}{l}\text { pelvic RT/bilateral orchiectomy/ AAT/ } \\
\text { prostate cryoablation }\end{array}$ \\
\hline $\begin{array}{l}\text { Liu et al. } \\
2015[9]\end{array}$ & 73 & $\begin{array}{l}\text { altered bowel } \\
\text { habits }\end{array}$ & $4+5=9$ & 1 year & $\begin{array}{l}\text { G3 / } \\
\text { adenocarcinoma }\end{array}$ & positive & $\begin{array}{l}\text { bilateral orchiectomy/AAT/ neoadjuvant } \\
\text { chemoradiotherapy }\end{array}$ \\
\hline
\end{tabular}

n.d no data, $P S A$ prostate-specific antigen, $R P$ radical prostatectomy, $L E$ local excision, $A R$ anterior resection, $R T$ radiotherapy, $A P R$ abdominoperineal resection, $A A T$ antiandrogen therapy

a two cases were excluded because of the continuity invasion to colon by PCa

prostate cancer cases. Metastases in digestive system are exceptionally rare. Formerly mentioned studies report only $1,8 \%$ and $2,7 \%$ of patients with metastatic disease in digestive system respectively [3].

In our case solitary prostate metastasis occurred in anal canal, which is extremely rare. Previously only seven cases reporting solitary prostate metastasis to colon and rectum can be found, which are summarized in Table 1. However, radical prostatectomy, as for our patient, was only performed in two cases $[4,5]$. In a case by Vaghefi et al. metastasis in rectum occurred 5 years after PCa diagnosis, which was treated with local excision [4]. In a second case by Venara et al. a prostatic carcinosarcoma occurred in rectum 10 years after initial $\mathrm{PCa}$ diagnosis and was treated with anterior rectum resection and radiotherapy [5]. In our case metastasis in anal canal appeared only 3 years after initial PCa diagnosis and was treated with abdominoperineal resection. Shorter period of time can be explained by relatively higher pathological Gleason sum of 9 (compared to 7 and 7 in previously mentioned cases) which has poorer prognosis.

Symptoms of prostate cancer metastasis to rectum are similar to primary rectal cancer. Patients can complain of constipation, abdominal pain, rectal bleeding, diarrhoea, tenesmus and weight loss which can be interpreted as primary rectal cancer. In a study by Wang et al. almost $17 \%$ of patients with prostate cancer involving rectum were misdiagnosed as primary rectal cancer [10]. Histopathological evaluation of rectal biopsy often may be the only way to differentiate between these two diseases. Positive staining for PSA and P501s is commonly seen in prostate adenocarcinoma, unlike rectal adenocarcinoma which distinguishes with positive CDX2, CK20 and beta-catenin staining and negative for PSA and P501s [10].
In our case patient had typical rectal cancer symptoms: dyschezia, pain in anal canal, and bloody stool. Radiological findings were not specific and only histopathological examination confirmed the $\mathrm{PCa}$ metastasis in anal canal. As the are only few reports on rectal involvement of prostate cancer, the cancer seeding is not understood well. At least few different paths of tumour cells seeding can be identified. First direct invasion through the Denonvilliers fascia or through lymphatic vessels. Vaghefi et al. theorized the possibility of tumour cell caused by implantation in the rectum after transrectal needle biopsy [4]. Alternatively, it is possible that tumour can be spilled at prostatectomy.

\section{Conclusions}

To conclude, our presented case is the first to describe prostate cancer solitary metastasis to anal canal and we always have to be aware of possible rare disease while assessing the patient with rectal bleeding. Biopsy most of the time is the only and the most reliable test to differentiate between the diseases.

\section{Abbreviations}

CT scan: Computed tomography scan; LVI: Lympho-vascular invasion; MRI: Magnetic nuclear resonance imaging; PCa: Prostate adenocarcinoma; PIRADS: Prostate Imaging Reporting and Data System; PSA: Prostate specific antigen

\section{Acknowledgements}

Not Applicable.

\section{Funding}

No financial support was received for this submission.

\section{Availability of data and materials}

The datasets used and/or analysed during the current study available from the corresponding author on reasonable request.

\section{Authors' contributions}

AD designed, performed the study and carried out literature search; VC helped in literature search and wrote the paper; FJ, EZ and ES helped in 
acquisition and analysis of data; $A D, E S$ and FJ made critical revision and supervision. All authors have read and approved the manuscript.

Ethics approval and consent to participate

Institutional review board of National Cancer Institute approval number 2018.05.01.

\section{Consent for publication}

Consent was signed by the patient for all the images, other personal and clinical details

\section{Competing interests}

The authors declare that they have no competing interests.

\section{Publisher's Note}

Springer Nature remains neutral with regard to jurisdictional claims in published maps and institutional affiliations.

\section{Author details}

'Department of General and Abdominal Surgery and Oncology, National Cancer Institute, 1 Santariskiu Str., LT-08406 Vilnius, Lithuania. ${ }^{2}$ Department of General and Abdominal Surgery and Oncology, National Cancer Institute, Clinic of Internal, Family Medicine and Oncology, Faculty of Medicine, 1 Santariskiu Str., LT-08660 Vilnius, Lithuania. ${ }^{3}$ University of Applied Sciences, Faculty of Health Care, 45 Didlaukio Str., Vilnius, Lithuania. ${ }^{4}$ National Center of Pathology, Affiliate of Vilnius University Hospital Santaros Klinikos, 5 P. Baublio Str., LT-08406 Vilnius, Lithuania. ${ }^{5}$ Department of Urology, National Cancer Institute, 1 Santariskiu Str., LT-08406 Vilnius, Lithuania.

Received: 11 November 2018 Accepted: 3 April 2019

\section{Published online: 23 April 2019}

\section{References}

1. Bray F, Ferlay J, Soerjomataram I, Siegel RL, Torre LA, Jemal A. Global cancer statistics 2018: GLOBOCAN estimates of incidence and mortality worldwide for 36 cancers in 185 countries. CA Cancer J Clin. 2018;68(6):394-424.

2. Smailyte G, Aleknaviciene B, Kaceniene A, Krilaviciute A, Lapasinskaite I, Meiluviene J, et al. Cancer in Lithuania 2012. National Cancer Institute; 2015. p. 4-5. http://www.nvi.lt/uploads/pdf/Nezio\%20registras/Nezys_lietuvoje_ 2012.pdf

3. Gandaglia G, Abdollah F, Schiffmann J, Trudeau V, Shariat SF, Kim SP, et al. Distribution of metastatic sites in patients with prostate cancer: a population-based analysis. Prostate. 2014;74(2):210-6.

4. Vaghefi H, Magi-Galluzzi C, Klein EA. Local recurrence of prostate cancer in rectal submucosa after transrectal needle biopsy and radical prostatectomy. Urology. 2005;66:881.e7-9.

5. Venara A, Thibaudeau E, Lebdai S, Mucci S, Ridereau-Zins C, Azzouzi R, Hamy A. Rectal metastasis of prostate cancer: about a case. J Clin Med Res. 2010;2:137-9.

6. Morita T, Meguro N, Tomooka Y, Maeda O, Saiki S, Kuroda M, et al. Rectal metastasis of prostatic cancer causing annular stricture: a case report. Hinyokika Kiyo. 1991;37:295-8.

7. Fujita T, Sakakibara M, Sobajima Y, Hosoda K, Ando T, Goto H. Colorectal metastasis of prostate cancer diagnosed by colonoscopy: a case report. Jpn Gastroenterol Endosc Soc. 2009;51:2897-904.

8. Nwankwo N, Mirrakhimov AE, Zdunek T, Bucher N. Prostate adenocarcinoma with a rectal metastasis. BMJ Case Rep. 2013;30(2013): bcr2013009503.

9. Liu Z-H, Li C, Kang L, Zhou Z-Y, Situ S, Wang J-P. Prostate cancer incorrectly diagnosed as a rectal tumor: a case report. Oncol Lett. 2015;9:2647-50.

10. Owens CL, Epstein Jl, Netto GJ. Distinguishing prostatic from colorectal adenocarcinoma on biopsy samples: the role of morphology and immunohistochemistry. Arch Pathol Lab Med. 2007;131:599-603.

\section{Ready to submit your research? Choose BMC and benefit from:}

- fast, convenient online submission

- thorough peer review by experienced researchers in your field

- rapid publication on acceptance

- support for research data, including large and complex data types

- gold Open Access which fosters wider collaboration and increased citations

- maximum visibility for your research: over $100 \mathrm{M}$ website views per year

At BMC, research is always in progress.

Learn more biomedcentral.com/submissions 